\title{
The effect of mutual task sharing on the number of needed health workers at the Iranian Health Posts; Does task sharing increase efficiency?
}

\author{
Ali Fakhri ${ }^{*}$, Aidin Aryankhesal ${ }^{2,3}$
}

\begin{abstract}
Background: Nowadays task sharing is a way to optimize utilization of human resources for health. This study was designed to assess the effect of task sharing, mutually between midwives and Family Health Workforces (FHWs), on the number of needed staff across the Iranian Health Posts.

Methods: The workload and required number of midwives and FHWs in a Health Post were calculated and compared in two different scenarios of task division using a combined approach for estimating the number of required staff. In the first scenario, the midwives and FHWs provide their specialized services and in the second one, using mutual task sharing, a midwife provides all services traditionally delivered by FHWs and each FHW provides prenatal care in addition to the special tasks. Sensitivity analysis was performed to estimate the effects of different hypotheses. Results: By applying mutual task sharing, the required number of staff for Health Posts was one midwife and two FHWs for a standard population of 12,500; one FHW less than that when no task sharing was applied. Sensitivity analysis illustrated that the number of needed staff is the same in both scenarios when different demographic, epidemiologic, cultural and organizational conditions were applied.

Conclusion: Task sharing can reduce the required number of health workers which increases efficiency and productivity at health facilities. However, apart from a need to consider quality, acceptability, and feasibility of care, increasing efficiency must be judged against the contextual circumstances.

Keywords: Workload Study, Human Resource for Health, Task Shifting, Task Sharing, Midwife, Health Post

Copyright: (c) 2015 by Kerman University of Medical Sciences

Citation: Fakhri A, Aryankhesal A. The effect of mutual task sharing on the number of needed health workers at the Iranian Health Posts; Does task sharing increase efficiency? Int J Health Policy Manag. 2015;4(8):511-516. doi:10.15171/ijhpm.2015.22
\end{abstract}

Article History:

Received: 16 September 2014 Accepted: 31 January 2015 ePublished: 6 February 2015

*Correspondence to:

Ali Fakhri

Email: fakhri-a@kaums.ac.ir

\section{Key Messages}

Implications for policy makers

- Task sharing is an approach to deal with human resource shortages, but it could also be used in a healthcare system with sufficient workforces to increase productivity with a regard to the demographic, epidemiologic, cultural, organizational and other circumstances.

- Mutual task sharing is a way to deal with the inappropriate distribution of workload between staff in health facilities.

- Although efficiency and access, two main goals of the healthcare system, could be attained through mutual task sharing, quality, the other key goal, should not be sacrificed in this type of task division.

\section{Implications for public}

Task sharing, a partnership in which different levels of health workers provide the same services, could be used mutually in health facilities. Sharing the tasks between various types of staff increases access, solves human resource shortage, increases productivity, and addresses the burden of new tasks considering the contextual conditions.

\section{Background}

Health workforce has an important role in the effectiveness of health systems considering this reality that staff's salaries have the biggest share in the health sector budgets $(1,2)$. So the allocation of an appropriate number of staff to healthcare organizations is necessary to achieve the optimized effectiveness and efficiency (3). Hence the goal of human resource planning is defined to make sure that the appropriate number of appropriate people is considered in the right place and right time (4).
To increase access to effective services, some strategies i.e. task shifting and task sharing are applied. These terms, used interchangeably due to the lack of precise definitions (5), refer to the delegation of tasks to the less specialized health workers $(6,7)$. It also refers to giving additional training to the existing cadres and then allow them take activities they have not undertaken before (5). In task shifting or task sharing, it is assumed that with adequate training, the less specialized health workers can provide competent services. Therefore these methods are in the interest of most systems to address 
their human resource shortage $(2,6,8)$ which experienced for example in providing HIV/AIDS care $(9,10)$, mental healthcare (11), family planning (12) and obstetric care (13). This approach also is applied in maternity care in which midwife tasks are moved to lay health workers (14). World Health Organization (WHO) document indicates the positive effect of these strategies to increase levels of healthcare access (5), if good management and political support and commitment are considered (6). Although evidence on costeffectiveness of the methods is limited, the conducted ones emphasize on economically successful aspects of them $(15,16)$. The related studies principally have focused on task shifting from physicians to nurses and from nurses to the logistic personnel, nurse-aids and other lay health workers (17). It is also possible to move tasks from midwives to other mid-level providers (5). In India the role of Auxiliary Nurse Midwife (ANM) who provide maternal services in closest facility to community, has been changed focusing on family planning and immunization (18). It is emphasized that nurses could have more roles in the maternity care, so shifting such tasks from midwives to nurses might decrease staff's salary costs (17) and antenatal counseling by non-professional nurse aids has as similar effectiveness as carrying that by nursemidwives (14).

In Iran, the nurses who provide mother and child care in the urban areas are named Family Health Workforces (FHWs). They provide family planning services, child care, elderly care and student care as their special tasks in facilities named Health Post. They are considered as multi-disciplinary personnel so trained to perform prenatal care as well. On the other hand, midwives are trained for the maternity care, as the main job, and child care, as additional task (19). They can provide maternal care, health training and consultation and family planning services (20). With regard to such capacities, in some districts, as a local policy, midwives provide other services such as child, elderly and student care in addition to their special services while the FHWs provide pre-pregnancy, pregnancy and post pregnancy care to their pre-determined population in the Health Posts. This reorganization of services has been performed in order to reduce needed staff and sharing the tasks between personnel. This study aimed to answer if mutual task sharing approach reduces the number of needed staff in the Iranian Health Posts.

\section{Methods}

In this study, the needed staff, i.e. midwife and FHW, was calculated in two scenarios; i) providing the specialized services by each personnel, and ii) providing services with mutual task sharing between two types of personnel, using the following formula (21) adapted from combination of two formulas; one used in utilization-based approach [Workload Indicators of Staffing Need (WISN) method] (22) and the other used in the need-based approach (Pileroodi method) (23);

Number of the required staff $=\frac{(\mathrm{k} \times \text { target population } \times \text { frequency } \times \text { standard activity })}{\text { Available working time }} \times$ coverage

The variables considered in this formula are briefly as follow: 1- Total population multiplied by demographic proportion of the target population of each service (target population)
2-Proportion of people who must be covered by the services $(\mathrm{k})$.

3- Anticipated coverage of service considered in operational plans in the district health center (anticipated coverage).

4- The frequency of service which should be provided to a person during one year (frequency).

5- The average time should be spent by health workers to provide a service (standard activity).

6- Available time for delivering health services in a year by each personnel (available working time).

Considering this above-mentioned framework (21) and using some recommendations from WISN and Pileroodi methods $(22,23)$, this study was done in following three steps:

\section{The first step: listing the services}

Kashan, a district that implemented mutual task sharing was selected due to its available data for our needed calculations. It covers 280,000 populations through 28 Health Posts to provide publicly mother and child care. Through consulting the related departments in Kashan district health center, services and service components that should be provided by FHW and midwife in a Health Post were listed. The list of services and their components were reviewed by a team including two midwives, two FHWs experienced in the Health Posts and two trainers related to these services from Behvarz Training Center. However, it should be noted that: 1. Based on the calculation of workload mentioned by Fakhri et al. each service should be considered as a whole (21), but considering service components could result in more precise determination of the standard activity (22), so activities under each service were listed as the service components.

2. According to the general regulations and principles announced by the Ministry of Health and Medical Education (MoHME) (24), the following tasks are considered as midwives' special tasks:

- IUD insertion (and IUD control);

- Addressing the referral cases from family planning program;

- Pap smear preparation;

- Special care for pregnant women.

3. We considered time spent for administrative tasks, trainings, and other overheads named allowance in WHO method in calculating available working time based on local references $(23,25)$.

The second step: timing the services and estimating the number of required staff

After listing the services, blank tables were used to collect data including above-mentioned variables separately for each service component. Then timing (per year) was done by designing a table according to the above-mentioned formula and variables with the following descriptions in a Microsoft Excel spreadsheet. Then the number of staff to provide those components and services were calculated.

The proportion of target group of each service was determined according to the composition of Kashan population adjusted from the national census in 2011. For example, the proportion of married women was assumed as the proportion of target population for family planning care because the Iranian cultural context does not permit it fall 
outside of this sub-population.

A proportion of the target group population who were eligible to receive the services or service components $(\mathrm{k})$ was determined using instructions which defined these eligibilities and the last annual statistics of them existing in the district health center. For example, all pregnant women were not eligible to receive special care during pregnancy. By multiplying two above-mentioned proportions by the total population, the number of the target group was calculated for each service component in the population.

The pre-determined objectives for services coverage in the operational plans are supposed as good indicator to determine the number of required human resources. So the anticipated coverage of the services was extracted from operational plans which codified by experts who are practitioners in district health center.

The frequency of service provision per client during a year was considered according to the related instructions produced by the MoHME presented at the time of this study. In the case of services composed of different components, the weighted mean of the component frequencies was considered. For example, the frequency of care for eligible women for family planning was different regarding to the kind of preventive devise, i.e. pills, condom, ampoule, IUD, tubectomy and vasectomy. Therefore, to calculate the frequency of such activities, the weighted mean of frequencies was considered. Regarding to the newness of some services or changes in some instructions or lack of standard time, either of three following methods were used for calculating the services time:

a. To determine the necessary time, according to the WISN method, viewpoints of experts in district health center as cadre group were used (22).

a. WISN emphasizes that determination of standard time to provide services, should be conducted by trained and motivated staff as facility group (22). So facility group including four experienced staff (two midwives and two FHWs) and also two trainers from Behvarz Training Center were selected. They were asked to estimate the average time for doing tasks from the start of activity to the end. They determined this time regarding to the total time of activity accomplish, information recording, preparing care tools and even the factors affected the time of providing services such as children's restlessness (25).

b. In order to triangulate the data, in addition to two abovementioned methods, the timing was done through role playing as well.

To measure time of providing services, the " $k \times$ target population $\times$ frequency $\times$ standard activity" of all services that should be provided per 12,500 people (the standard catchment area population for a Health Post) was calculated separately for midwife and FHW. The workload of both personnel was calculated once for specialized services as scenario 1 and once for specialized services in addition to shared services as scenario 2 .

To measure the number of required staff who provides services in a year, the total time covered for services was divided by Availability Working Time in a one-year period as the above-mentioned formula shows. The Availability Working Time was assumed 250 work days for each employee in a year and six work hours a day, i.e. 90,000 minutes per year (23).

The third step: comparison of required staff in different forms of task division

Workload and numbers of midwife and FHW were measured once with this assumption that they provide specialized services as scenariol and once in the present form of task division in Kashan as scenario 2 and then the results were compared considering the following points:

1- Health Posts are open for delivering services from 7 to $14: 30$. On the other hand, a given population has been defined for each personnel so health system is responsive to attendance of fulltime personnel and the workforce number cannot be in the form of fractional so the numbers were rounded according to the following method and considering that employees should bear $10 \%$ extra work (22):

$1.0-1.1$ was rounded down to $1 ; 1.11-1.9$ was rounded up to 2 ; 2.0-2.2 was rounded down to $2 ; 2.21-2.9$ was rounded up to 3 ; $3.0-3.3$ was rounded down to $3 ; 3.31-3.9$ was rounded up to 4 . 2 - We calculated the number of needed staff based on service coverage anticipated and " $k$ " coefficient suggested by district health center so a one-way sensitivity analysis was conducted to assess comparison results by changing these variables in the formula.

3- Considering the fact that varying covered population, less or more than standard of 12,500 , and also varying actual working hours, less or more than six hours, would change the number of needed workforces (23), a threshold sensitivity analysis was carried out.

\section{Results}

The IUD insertion and its control, addressing complicated family planning cases, the mothers' health program and the group health training of related groups were listed as midwife special services in the Health Post. Family planning programs, healthy child programs, elderly health programs, students' health programs, health communicators programs (female volunteers) and health training of related groups were introduced as the special health services should be provided by FHWs. According to this study, through task sharing, prenatal care of covered population was added to FHW tasks and mutually, FHW tasks were added to midwife tasks (Tables 1 and 2).

Regarding the total services, the workload presented in a Health Post with a standard population of 12,500 would be about 270 thousand minutes per year. The required staff number to provide total services, with annually 250 working days and six hours per day would be three staff (Table 3). Hence, in the first scenario of task division in which the employed midwives provides just their own special services, 44,115 minutes per year will be needed and so 0.49 midwives is required. In addition, $2.51 \mathrm{FHWs}$ are needed to cover the remaining services. Consequently, when the staff numbers are rounded up, one midwife and three FHWs are required (Table 3 ). The midwives' workload under this condition would be $16 \%$ of the total workload and therefore midwifes' workload is about $60 \%$ of FHW workload.

In the second scenario of task division with mutual task sharing, one midwife and only two FHWs are required. In this condition, the midwife and FHW workloads have been 
Table 1. Comparison of special tasks of midwife and FHW in the scenario 1

\begin{tabular}{|c|c|}
\hline Midwife & FHW \\
\hline $\begin{array}{l}\text { - IUD insertion and control } \\
\text { - To meet reference cases of } \\
\text { family planning }\end{array}$ & $\begin{array}{l}\text { Family planning } \\
\text { Except: } \\
\text { - IUD insertion and control } \\
\text { - To meet reference cases of } \\
\text { family planning }\end{array}$ \\
\hline- & Healthy child program \\
\hline Mothers' health program & - \\
\hline- & Elders' health program \\
\hline- & Students' health program \\
\hline- & Health communicators program \\
\hline $\begin{array}{l}\text { Group health training (related } \\
\text { issues) }\end{array}$ & $\begin{array}{l}\text { Group health training (related } \\
\text { issues) }\end{array}$ \\
\hline
\end{tabular}

FHW= Family Health Workforce

Table 2. Comparison of shared tasks of midwife and FHW in the scenario 2

\begin{tabular}{|c|c|}
\hline Midwife & FHW \\
\hline $\begin{array}{l}\text { Family planning } \\
\text { With: } \\
\text { - IUD insertion and control } \\
\text { - To meet reference cases of } \\
\text { family planning }\end{array}$ & $\begin{array}{l}\text { Family planning } \\
\text { Except: } \\
\text { - IUD insertion and control } \\
\text { - To meet reference cases of } \\
\text { family planning }\end{array}$ \\
\hline Healthy child program & Healthy child program \\
\hline $\begin{array}{l}\text { Mothers' health program } \\
\text { With: } \\
\text { - Pap smear preparation } \\
\text { - Special care for pregnant } \\
\text { women }\end{array}$ & $\begin{array}{l}\text { Mothers' health program } \\
\text { Except: } \\
\text { - Pap smear preparation } \\
\text { - Special care for pregnant } \\
\text { women }\end{array}$ \\
\hline Elders' health program & Elders' health program \\
\hline Students' health program & Students' health program \\
\hline Health communicators program & Health communicators program \\
\hline $\begin{array}{l}\text { Group health training (related } \\
\text { issues) }\end{array}$ & $\begin{array}{l}\text { Group health training (related } \\
\text { issues) }\end{array}$ \\
\hline
\end{tabular}

FHW= Family Health Workforce

equally divided by calculated dividing of covered population between them (Table 4).

According to the first scenario, the midwife workload is $49 \%$ of the capacity and FHW workload is $84 \%$. Nonetheless with mutual task sharing with supposed conditions, $100 \%$ of both midwife and FHW capabilities is used (Table 5).

One-way sensitivity analysis illustrated that assuming full coverage of services which traditionally occurs in need-based approach for estimating of required staff, we need three FHWs and one midwife in the both scenarios. The elderly healthcare program, a new integrated program, is in the initial steps of implementation, covering a part of elders defined as eligible target group. We assumed the implementation was complete, to do another sensitivity analysis that illustrated the same numbers of personnel in both scenarios.

Threshold sensitivity analysis also showed how many personnel are needed if the covered populations of Health Posts and actual working hours are varied (see Tables 6 and 7).

\section{Discussion}

What was tested in the Health Posts of Kashan city was a mutual task sharing. Through the task sharing process parts of midwife tasks were delegated to the FHW and vice versa. Our study results conclude that if midwife and FHW provide only their traditional services, they would use only $49 \%$ and $84 \%$ of their capability respectively. However by task sharing, $100 \%$ of staff capability would be used which improves productivity. A midwife covers all assigned services in a Health Post with a standard population in all scenarios, but providing prenatal care by one person decreases population access to such care when the midwife is absent. Therefore mutual task sharing improves the accommodation dimension of access to the care defined by Penchansky and Thomas (26) that means a pregnant women would receive necessary care even in the absence of midwife, e.g. due to vacation or illness.

The sensitivity analysis illustrated that task sharing allows district health center to cover the demanded services in a Health Post, with less than 4,000 population, by one midwife while without task sharing it is necessary to employ at least one midwife and one FHW. One midwife and two FHWs are needed if the Health Post's catchment area population is 9,000 to 14,000 , in scenario 2 . This range is close to the standard population suggested by the MoHME $(12,500)$ and also close to the mean population of each Health Post in Kashan $(10,000)$. By scaling up the covered populations through scenario 1, bigger part of midwife capacity is used. Hence, in high-density areas that health system cannot add facilities but prefer to add personnel to a Health Post, in the threshold of 29,000 populations, the results of the scenarios would be similar. The sensitivity analysis also illustrated that scaling the actual working hours down, due to the cultural or organizational factors (27), has a similar effect when the population is scaled up. Considering the role of variables i.e. service coverage, integrated new programs, covered

Table 3. Comparison of midwife and FHW workload in a Health Post by minutes in scenario 1

\begin{tabular}{|c|c|c|c|c|}
\hline Personnel & Workload & Required staff numbers & Rounded Required staff numbers & Proportion (\%) \\
\hline Midwife & 44,115 & 0.49 & 1 & 16 \\
\hline FHW & 226,026 & 2.51 & 3 & 84 \\
\hline Total & 270,141 & 3.00 & 4 & 100 \\
\hline
\end{tabular}

FHW= Family Health Workforce

Table 4. Comparison of midwife and FHW workload in a Health Post by minutes in scenario 2

\begin{tabular}{|c|c|c|c|c|}
\hline Staff & Workload & Required staff numbers & Rounded Required staff numbers & Proportion (\%) \\
\hline Midwife & 90,047 & 1 & 1 & 33.33 \\
\hline FHW & 180,094 & 2 & 2 & 66.66 \\
\hline Total & 270,141 & 3 & 3 & 100.00 \\
\hline
\end{tabular}

FHW= Family Health Workforce 
Table 5. Comparison of the used capacity of midwife and FHW in two types of task division

\begin{tabular}{lcc}
\hline \multirow{2}{*}{ Staff } & \multicolumn{2}{c}{ Task dividing } \\
\cline { 2 - 3 } & Special tasks & Shared tasks \\
\hline Midwife & $49 \%$ & $100 \%$ \\
FHW & $84 \%$ & $100 \%$ \\
\hline
\end{tabular}

FHW= Family Health Workforce

Table 6. The number of needed staff in the variation of covered population of Health Posts

\begin{tabular}{lcc}
\hline \multirow{2}{*}{ Staff } & \multicolumn{2}{c}{ Population } \\
\cline { 2 - 3 } & Scenario 1 & Scenario 2 \\
\hline One midwife & - & $<4,000$ \\
One midwife and one FHW & $<5,000$ & $4,000-9,000$ \\
One midwife and two FHWs & $5,000-11,000$ & $9,000-14,000$ \\
One midwife and three FHWs & $11,000-17,000$ & $14,000-19,000$ \\
One midwife and four FHWs & $17,000-23,000$ & $19,000-24,000$ \\
One midwife and five FHWs & $23,000-29,000$ & $24,000-29,000$ \\
Two midwives and five FHWs & - & $29,000-34,000$ \\
Two midwives and six FHWs & $29,000-35,000$ & $34,000-39,000$ \\
\hline
\end{tabular}

FHW= Family Health Workforce

Table 7. The number of needed staff in the variation of actual working hours in the Health Post

\begin{tabular}{lcc}
\hline \multirow{2}{*}{ Staff } & \multicolumn{2}{c}{ Population } \\
\cline { 2 - 3 } & Scenario 1 & Scenario 2 \\
\hline One midwife and two FHWs & $7: 20-6: 50$ & $7: 20-5: 27$ \\
One midwife and three FHWs & $6: 50-4: 35$ & $5: 27-4: 05$ \\
One midwife and four FHWs & $4: 35-3: 25$ & $4: 05-3: 16$ \\
One midwife and five FHWs & $3: 25-2: 44$ & $3: 16-2: 43$ \\
One midwife and six FHWs & $2: 44-2: 40$ & $2: 43-2: 40$ \\
Two midwives and five FHWs & - & $2: 40-2: 20$ \\
Two midwives and six FHWs & $2: 40-2: 17$ & $2: 20-2: 03$ \\
\hline
\end{tabular}

FHW= Family Health Workforce

population and actual working hours in the above-mentioned equation, it is emphasized the significance of demographic, epidemiologic, cultural and organizational circumstances on optimizing health worker roles through task sharing.

Pileroodi had suggested one midwife and three FHWs to provide necessary services for a population of 12,000 , emphasizing that 234,000 minutes would be needed per annum in an Iranian Health Post (23). Therefore providing more services by three staff while applying mutual task sharing for their tasks would improve the efficiency.

Although task shifting and task sharing have been suggested to compensate human resource shortage, our study illustrates that this approach can increase productivity. This could entail an opportunity for integration of new programs in the facilities without employing new workforces. In fact, this study sends a message that the focus could be on appropriate task sharing in facilities with sufficient human resources to increase productivity as well as task shifting to address human resource shortage.

Some studies indicate that midwives can provide nonspecialized in order to increase efficiency. According to Seran et al. study, midwives carry out non-maternity care such as elderly care, school care and tuberculosis and malaria care that fill $50 \%$ of their time in Indonesia (28). Fulton et al. in their review also emphasize on this approach as a policy option to increase efficiency and productivity (29). On the other hand, changing the role of ANM from a midwife whose main job was to deliver babies and maternal and child healthcare, to a paramedical whose activities are limited to family planning, immunization and superficial antenatal care, has been criticized because of decreasing performance of ANM and insufficient maternal mortality in India (18). Therefore despite of emphasizing on shifting tasks from midwives to other health workers in order to access (5), the quality of care, feasibility and acceptability also should be considered $(7,11)$. Our study also emphasizes on considering the contextual conditions to judge about efficiency in task sharing. This is what emphasized by Ranson et al. (30) as well for managing health system human resources.

\section{Conclusion}

Task sharing between midwives and FHWs mutually in the Health Posts leads to equally task division. This approach can reduce the required number of health workers and so increase the efficiency at health facilities with workforce shortage and increase productivity across ones with sufficient workforce. But apart from the need to consideration of quality of care, acceptability and feasibility through task sharing, any judgment on efficiency must be passed by considering contextual conditions.

One limitation of this study is focusing only on the significance of efficiency. Our study strength is the detailed calculation of needed workforces.

\section{Acknowledgements}

This work was supported by the Deputy of Research, Kashan University of Medical Sciences, Kashan, Iran. We are also grateful for contributing through data collection from the personnel of the Kashan Health Center.

\section{Ethical issues}

The study was a cross-sectional study to calculate the required number of staff and conducting sensitivity analysis on data extracted from annual statistics (i.e. secondary data). As such, no ethical approval was required for this study.

\section{Competing interests}

The authors declare that they have no competing interests.

Authors' contributions

AF designed the study, managed data collection and conducted the analysis. AA contributed to critical revision of the manuscript and re-drafted the paper for English speaking audiences.

\section{Authors' affiliations}

${ }^{1}$ Social Determinants of Health $(\mathrm{SDH})$ Research Center, Kashan University of Medical Sciences, Kashan, Iran. ${ }^{2}$ Health Management and Economics Research Center, Iran University of Medical Sciences, Tehran, Iran. ${ }^{3}$ School of Health Management and Information Sciences, Iran University of Medical Sciences, Tehran, Iran.

\section{Reference}

1. World Health Organization (WHO). The World health report 2000: health systems : improving performance. Geneva: WHO; 2000.

2. World Health Organization (WHO). The World Health Report 2006: Working together for health. Geneva: WHO; 2006.

3. Daviauda E, Chopra M. How much is not enough? Human resources requirements for primary health care: a case study 
from South Africa. Bull of the World Health Org 2008; 86: 46-51. doi: $10.2471 /$ BLT.07.042283

4. Dreesch N, Dolea C, Dal Poz MR, Goubarev A, Adams O, Aregawi $\mathrm{M}$, et al. An approach to estimating human resource requirements to achieve the Millennium Development Goals. Health Policy Plan 2005; 20: 267-76. doi: 10.1093/heapol/czi036

5. World Health Organization (WHO). WHO recommendations; Optimizing health worker roles to improve access to key maternal and newborn health interventions through task shifting. Geneva: WHO; 2012.

6. World Health Organization (WHO). Task shifting to tackle health worker shortages. Geneva: WHO; 2007.

7. WHO/PEPFAR/UNAIDS. Task shifting : rational redistribution of tasks among health workforce teams : global recommendations and guidelines. Geneva: WHO; 2008.

8. Hagopian A, Micek MA, Vio F, Gimbel-Sherr K, Montoya P. What if we decided to take care of everyone who needed treatment? Workforce planning in Mozambique using simulation of demand for HIVIAIDS care. Hum Resour Health 2008; 6: 3.

9. Jerome J, Ivers L. Community health workers in health systems strengthening: a qualitative evaluation from rural haiti. AIDS 2010; 24: S67-72. doi: 10.1097/01.aids.0000366084.75945.c9

10. The United States Agency for International Development (USAID). Creating an enabling environment for task shifting in HIV and AIDS services: recommendations based on two African country case studies. Washington DC: USAID; 2010.

11. Padmanathan P, Silva MJ. The acceptability and feasibility of task-sharing for mental healthcare in low and middle income countries: a systematic review. Soc Sci Med 2013; 97: 82-6. doi: 10.1016/j.socscimed.2013.08.004

12. Janowitz B, Stanback J, Boyer B. Task sharing in family planning. Stud Fam Plann 2012; 43: 57-61. doi: 10.1111/j.17284465.2012.00302.x

13. Gessessew A, Barnabas GA, Prata N, Weidert K. Task shifting and sharing in Tigray, Ethiopia, to achieve comprehensive emergency obstetric care. Int J Gynaecol Obstet 2011; 113: 2831. doi: 10.1016/j.ijgo.2010.10.023

14. Jennings L, Yebadokpo AS, Affo J, Agbogbe M, Tankoano A. Task shifting in maternal and newborn care: a non-inferiority study examining delegation of antenatal counseling to lay nurse aides supported by job aids in Benin. Implement Sci 2011; 6: 2 .

15. Buttorff C, Hock RS, Weiss HA, Naik S, Araya R, Kirkwood $\mathrm{BR}$, et al. Economic evaluation of a task-shifting intervention for common mental disorders in India. Bull World Health Organ 2012; 90: 813-21. doi: 10.2471/BLT.12.104133

16. Babigumira JB, Castelnuovo B, Stergachis A, Kiragga A, Shaefer $\mathrm{P}$, Lamorde $\mathrm{M}$, et al. Cost Effectiveness of a Pharmacy-Only Refill Program in a Large Urban HIVIAIDS Clinic in Uganda.
PLoS One 2011; 6: e18193. doi: 10.1371/journal.pone.0018193

17. Sandall J, Homer C, Sadler E, Rudisill C, Bourgeault I, Bewley $\mathrm{S}$, et al. Staffing in Maternity Units: Getting the right people in the right place at the right time. London: The King's Fund; 2011.

18. Mavalankar D, Vora KS. The Changing Role of Auxiliary Nurse Midwife (ANM) in India: Implications for Maternal and Child Health $(\mathrm{MCH})$. Ahmedabad: Indian Institute of Management; 2008.

19. Deputy Ministry for Education, Ministery of Health and Medical Education [homepage on the internet]. [cited 2014 Sep. 29]. Available from: http://mbs.behdasht.gov.ir/uploads/176_315_ moshakhasat_KNbehdashtomomi.pdf

20. Bahadoran P, Alizadeh S, Valiani M. Exploring the Role of Midwives in Health Care System in Iran and the World. Iranian Journal of Nursing and Midwifery Research 2009;14: 117-22.

21. Fakhri A, Seyedin H, Daviaude E. A combined approach for estimating health staff requirements. Iran J Public Health 2014; 43: 107-15.

22. World Health Organization (WHO). Workload indicators of staffing need.User's manual. Geneva: WHO; 2010.

23. Pileroodi S. District health network. 3rd edition. Tehran: Razavieh publication; 2006. [In persian]

24. Ministry of Health and Medical Education (MoHME). General Regulations and Principles in the Structure of Development Programs of District Health Networks. Tehran: Network Development and Health Promotion Center of MoHME; 2007. [In persian]

25. Pileroodi S. Integrated services and a method for assessing human resource. 1st edition. Tehran: Aghigh publication; 1997. [In persian]

26. Penchansky R, Thomas JW. The concept of access: definition and relationship to consumer satisfaction. Med Care 1981; 19: 127-40. doi: 10.1097/00005650-198102000-00001

27. Shipp PJ. Workload indicators of staffing need (WISN): A manual for implementation. Geneva: WHO; 1998.

28. Seran SB, Kromoredjo P, Kolehmainen-Aitken RL, Smith J, Darmawan J. Decentralised application of the WISN methodology in the Nusa Tenggara Timur Province. Indonesia: EPOS Health Management; 2009.

29. Fulton BD, Scheffler RM, Sparkes SP, Auh EY, Vujicic M, Soucat A. Health workforce skill mix and task shifting in low income countries: a review of recent evidence. Hum Resour Health 2011; 9: 1. doi: 10.1186/1478-4491-9-1

30. Ranson MK, Chopra M, Atkins S, Pozc MRD, Bennetta S. Priorities for research into human resources for health in lowand middle-income countries. Bull World Health Organ 2010; 88: 435-43.doi: 10.2471/BLT.09.066290 